\title{
Carnets
}

Revue électronique d'études françaises de l'APEF

Deuxième série - 19 | 2020

Petite fabrique d'interprètes

\section{George Steiner ou le comparatiste en tant qu'interprète universel}

\section{Álvaro Manuel Machado}

\section{(2) OpenEdition}

1 Journals

Édition électronique

URL : http://journals.openedition.org/carnets/11577

DOI : 10.4000/carnets. 11577

ISSN : 1646-7698

Éditeur

APEF

Référence électronique

Álvaro Manuel Machado, « George Steiner ou le comparatiste en tant qu'interprète universel », Carnets [En ligne], Deuxième série - 19 | 2020, mis en ligne le 31 mai 2020, consulté le 22 décembre 2020. URL : http://journals.openedition.org/carnets/11577 ; DOI : https://doi.org/10.4000/carnets. 11577

Ce document a été généré automatiquement le 22 décembre 2020.

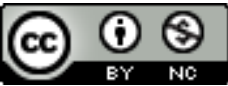

Carnets est mis à disposition selon les termes de la licence Creative Commons - Atribution - Pas d'utilisation commerciale 4.0 International. 


\title{
George Steiner ou le comparatiste en tant qu'interprète universel
}

\author{
Álvaro Manuel Machado
}

1 George Steiner, décédé récemment, doit être considéré, par son œuvre immense et très originale, parfois polémique, le plus extraordinaire, disons, philosophe des cultures les plus diverses du XXe siècle, sans oublier son côté polyglotte et son attachement profond à la France (il est né à Paris en 1929) et à la littérature française. Comparatiste attitré, toujours à la recherche des " arts du sens ", il a consacré une grande partie de ses recherches à la fonction du lecteur en tant qu'interprète, notamment à travers l'interprétation du traducteur, interprète privilégié des cultures, dans son chefd'œuvre After Babel (1975). Un passage de ce livre, traduit en français, nous servira de point de départ théorique :

La traduction d'une langue A dans une langue B concrétise l'implication d'une troisième présence active. Elle révèle la physionomie du "pur langage » qui a précédé et qui sous-tend les deux langues. Une authentique traduction dégage les contours vagues mais reconnaissables du dessin cohérent dont, après Babel, se sont détachés les fragments torturés du langage humain. (...) Le traducteur enrichit sa langue en laissant la langue-source s'y insinuer et la modifier. Mais il fait bien plus : il étire son propre parler en direction de l'absolu secret de la signification (Steiner, $1978: 71-72)$.

2 Beaucoup plus tard, dans un texte intitulé «Lire en frontalier », daté de 1994 - leçon inaugurale de la première chaire de littérature comparée à Oxford - Steiner revient sur cette idée de la recherche de «l'absolu secret de la signification » d'un texte et d'une langue, en la transposant vers la fonction primordiale du comparatiste :

Je conçois la littérature comparée, au mieux, comme un art de lire tout d'exactitude et d'exaction (je veux dire par là d'astreinte), comme un style d'écouter aux actes du langage, oral ou écrit, qui privilégie certains éléments de ces actes. En aucun genre d'étude littéraire on ne néglige ces éléments-là, mais, en littérature comparée, je répète qu'on les privilégie. (...) Bref, la littérature comparée est un art de comprendre centrée sur le résultat possible de la traduction et sur ses échecs (Steiner, 1997 : 130-131). 
En fait, ce texte de George Steiner en tant que professeur de littérature comparée à l'Université d'oxford est fondamental pour pouvoir comprendre tout son parcours intellectuel, particulièrement en ce qui concerne son idée de la fonction du comparatiste en tant qu'intermédiaire, ou plus exactement, interprète privilégié des œuvres littéraires et des cultures étrangères à travers les siècles. Ou encore, comme il le dit lui-même: sa fonction d'étudier "la dissémination et la réception des œuvres littéraires à travers temps et lieux » (ibid. : 133).

4 Voyons comment cette idée de la fonction du comparatiste en tant qu'interprète privilégié des œuvres littéraires étrangères «à travers temps et lieux » est développée tout au long de son œuvre immense, à partir d'After Babel.

5 Dans un texte de 1978 sur la signification d'une toile du peintre français Chardin, datée de 1734 et intitulée Un philosophe occupé de sa lecture, George Steiner analyse en détail le thème de cette toile, c'est-à-dire, le rapport qu'entretient le livre avec le temps. Pour lui, s'il est vrai que « la vie du lecteur se mesure en heures » tandis que celle du livre se mesure « en millénaires » (ibid: 13), il n'est pas moins vrai que chaque lecteur est à son époque un interprète différent de la matière de ce livre. Ainsi, une œuvre littéraire traverse des siècles et des siècles parce qu'elle est, disons, transfigurée à chaque fois par les multiples lecteurs à travers le monde et les langues (question essentielle en termes de réception pour le comparatiste), en se nourrissant, comme c'est le cas paradigmatique des Essais de Montaigne, du «tissage vivant d'échos et de citations » (ibid: 20). Autrement dit, pour Steiner est fondamentale que l'acte de lire soit, en passant par l'imagination et la culture propres à chaque lecteur, une "relation créatrice » : «Le vrai lecteur entretient avec le livre une relation créatrice. Le livre a besoin de lui autant que le lecteur a besoin du livre : égalité de confiance que rend exactement la composition de Chardin. C'est au sens le plus concret que chaque acte de lecture authentique, toute 'lecture bien faite', est une collaboration avec le texte " (ibid: 33).

6 À un niveau différent de la réflexion sur la fonction du lecteur dans le domaine spécifique de la littérature comparée et du comparatiste en tant qu'interprète, intermédiaire entre cultures différentes, Steiner analyse en profondeur la question du « sens » de l'œuvre littéraire dans Réelles présences. Les arts du sens.

7 Dès l'avant-propos à l'édition française, parue en 1991, de Real Presences. Is there anythig in what we say? (1989), Steiner, après avoir cité un passage de Notes nouvelles sur Edgar Poe de Baudelaire, s'attaque à la lecture de tendance dite "déconstructionniste", devenue prédominante surtout à partir des années 70 et des théories de Derrida, comme on le sait: «Ce sont autant de non-lectures préfabriquées qui transforment un texte en prétexte, des lectures qui renversent les valeurs et inversent les priorités ontologiques. (...) Autant de mésententes, d'incapacité à l'écoute, de surdité de l'esprit. Aurions-nous peur de l'indiscrétion du 'révélé' ? (...) » (Steiner, $1991: 12$ ).

8 S'il fait l'éloge de ce que Baudelaire appelle « l'exil dans l'imparfait », c'est pour exalter « ce miracle que nous appelons le sens, l'entendement de l'Autre » (ibid: 13).

9 Tout au long du livre, Steiner revient sur cet «entendement de l'Autre », dans une perspective d'interprétation du texte littéraire (mais aussi d'une œuvre musicale ou d'un tableau) essentiellement comparatiste et universelle. À noter qu'il utilise spécifiquement le mot « interprète », en le définissant de façon précise : 
Un interprète, c'est un individu qui déchiffre et communique des significations. C'est un traducteur d'une langue à une autre, d'une convention de représentation à une autre. (...) l'interprétation est une compréhension en action (...). Ce type de compréhension est simultanément analytique et critique. (...) il s'agit d'un acte d'approfondissement et de réponse qui rend sensible le sens. (...) l'interprète fait l'investissement de son être dans le processus de l'exécution (ibid : 26-27).

Cette dimension ontologique de l'interprète est développée tout au long du livre, aussi bien que l'idée de la découverte de l'«autre », fondamentale pour le vrai comparatiste. Voici pourquoi, plus loin, Steiner met en relief ces éléments essentiels de la fonction de ce qu'il appelle « interprète »:

Si le langage, si l'art existent, c'est parce que existe l'«autre ». Certes, nous nous adressons à nous-mêmes en un soliloque constant. Mais le médium de ce soliloque est celui du langage commun. (...) Le ravissement de Narcisse est, de manière tautologique, de l'ordre du suicide. Et Narcisse n'a aucun besoin de l'art. (...) Le sens, les modes d'existence de l'art, de la musique comme de la littérature, relèvent de l'expérience de notre rencontre avec l'autre (idem : 169-170).

11 En conclusion, on peut dire que pour George Steiner, lorsque dans son œuvre immense il se consacre plus particulièrement aux études de littérature comparée, au-delà même de certaines réflexions générales de caractère plus philosophique, le comparatiste est avant tout un interprète privilégié de l'«autre", dans une perspective vraiment universelle. Une perspective théorique très vaste, laquelle s'étend à la fois aux domaines esthétiques, des idées et des langues.

\section{BIBLIOGRAPHIE}

STEINER, George (1978). Après Babel : une poétique du dire et de la traduction (Édition française de After Babel. Oxford University Press : 1975). Paris : Albin Michel.

STEINER George (1997). Passions impunies (Édition française de No Passion Spent (Essays 1978-1996).

Londres : Faber and Faber, 1996). Paris : Gallimard.

STEINER, George (1991). Réelles présences. Les arts du sens (Édition française de Real Presences. Is there anythig in what we say?. Londres: Faber and Faber, 1989). Paris: Gallimard.

\section{RÉSUMÉS}

George Steiner, décédé récemment, est né à Paris en 1929 et, tout au long de son œuvre immense d'essayiste, a été toujours très attaché à la littérature et, en général, à la culture française. Maître à penser, européen convaincu, polyglotte, érudit, Steiner a été professeur de littérature comparée à l'université d'Oxford. Comparatiste attitré, toujours à la recherche des «arts du sens ", il a consacré une grande partie de ses recherches à l'étude de la fonction du lecteur en tant qu'interprète de l'«autre». Le point de départ de ces recherches spécifiquement comparatistes est son chef-d'œuvre After Babel (1975), où il approfondit la notion de la fonction du traducteur en tant qu'interprète des œuvres littéraires et des cultures étrangères à travers les 
siècles. Le long parcours de ces recherches s'étend jusqu'en 1994, année de la publication d'un texte spécifique sur la fonction du comparatiste intitulé, dans l'édition française du livre No Passion Spent (Essays 1978-1996), "Lire en frontalier ", leçon inaugurale de la première chaire de littérature comparée à l'Université d'Oxford.

George Steiner, who died recently, was born in Paris in 1929 and, throughout his immense work as an essayist, was always very attached to literature and, in general, to French culture. Maitre à penser, convinced European, polyglot and scholar, Steiner was a professor of comparative literature at the University of Oxford. A dedicated comparatist, always in search of the "arts of meaning", he devoted a large part of his research to the study of the function of the reader as an interpreter of the "other". The starting point for this specifically comparative research is his masterpiece After Babel (1975), in which he deepens the notion of the translator's function as an interpreter of literary works and foreign cultures over the centuries. The long course of this research extends until 1994, the year of the publication of a specific text on the function of the comparatist entitled, in the French edition of the book No Passion Spent (Essays 1978-1996), "Reading across borders", inaugural lesson of the first chair of comparative literature at the University of Oxford.

\section{INDEX}

Keywords : comparatist, interpreter, other, universality, déconstructionnism, arts of sens

Mots-clés : comparatiste, interprète, l'autre, universalité, déconstructionnisme, arts du sens

\section{AUTEUR}

\section{ÁLVARO MANUEL MACHADO}

Universidade Nova de Lisboa

am.machado[at]sapo.pt 